\title{
TITLE:
}

\section{Arrangement of foot interosseous muscles in African great apes}

\author{
$\operatorname{AUTHOR}(\mathrm{S})$ :
}

Hirasaki, Eishi; Oishi, Motoharu

\section{CITATION:}

Hirasaki, Eishi ... [et al]. Arrangement of foot interosseous muscles in African great apes. American Journal of Physical Anthropology 2018, 167(4): 924-929

\section{ISSUE DATE:}

2018-12

URL:

http://hdl.handle.net/2433/235247

\section{RIGHT:}

This is the accepted version of the following article: [Eishi Hirasaki, Motoharu Oishi. Arrangement of foot interosseous muscles in African great apes. American Journal of Physical Anthropology, 167(4) 924-929], which has been published in final form at https://doi.org/10.1002/ajpa.23685. This article may be used for non-commercial purposes in accordance with Wiley Terms and Conditions for Self-Archiving.; The full-text file will be made open to the public on 17 November 2019 in accordance with publisher's 'Terms and Conditions for Self-Archiving': This is not the published version. Please cite only the published version.; この論文は出版社版でありません。引用の祭には出版社版をご確認ご利用ください。 
1 Title: Arrangement of foot interosseous muscles in African great apes

2

3

4

5

6 Names of the authors: Eishi HIRASAKI ${ }^{1}$, Motoharu OISHI

7

8 Institutional affiliations:

$9{ }^{1}$ Section of Evolutionary Morphology, Primate Research Institute, Kyoto University, 10 Inuyama, Aichi 484-8506, Japan,

112 Laboratory of Anatomy 1, School of Veterinary Medicine, Azabu University,

12 Sagamihara, Kanagawa 252-5201, Japan.

Text: 14 pages. including the title ( 1 page), abstract ( 1 page), text ( 8 pages), references (3 pages), figure legends (1 page).

Figures: 3

Table: 1

\section{Grant sponsorship:}

The Japan Society for the Promotion of Science provided partial financial support for this study (Grants-in-Aid for Scientific Research, 15H04428 for EH). We declare we have no competing interests.

\section{Correspondence to:}

Eishi HIRASAKI

Kyoto University, Primate Research Institute, Inuyama, Aichi 484-8506, Japan,

Tel: +81-568-63-0520; Fax: +81-568-61-5775

Email: hirasaki.eishi.6x@kyoto-u.ac.jp 


\section{$33 \quad$ Abstract}

Objectives: The dorsal interossei of the human foot are arranged so that they abduct the digits around the second digit, while those of non-hominoid anthropoid primates are mostly arranged around the third or fourth digit. This is thought to relate to the medial shift in the functional axis, an essential modification in the evolution of the human foot. However, studies of the arrangement of interosseous muscles are relatively limited and there is some debate about their arrangement in great apes. In particular, some researchers claim that the interossei of chimpanzees are arranged around the second digit, whereas others claim that their foot axis lies on the third digit.

Materials and Methods: We examined the arrangement of the foot interosseous muscles in ten chimpanzees, one bonobo, and three gorillas.

Results: The interossei were arranged around the second digit in two chimpanzees, one bonobo, and one gorilla, whereas the third digit was the axis in the other specimens.

Discussions: The variation observed suggests that the arrangement of the interosseous 8 muscles of the great apes is in a transitional condition from monkey-type to human-type. Considering that osteological and foot pressure research supports the idea that the foot axis is on the second digit in great apes, modification in the interosseous muscles appears 1 to lag behind modification in the metatarsals and foot motion.

4 Key words: functional foot axis, bipedal locomotion, medial shift, dorsal interossei 


\section{INTRODUCTION}

Plantar pressure distribution in humans during bipedal walking is characterized by the heel touching the ground first followed by the first or second digit pushing off the ground. During this motion — specifically just before pushing off the ground-force is transmitted along a line connecting the talocrural joint and the head of the first or second metatarsal. This virtual line acts as a lever during walking and was described as "the functional axis of the foot" by Morton (1922). Previous studies on plantar pressure measurement suggest that there was a medial shift in the functional foot axis during the course of hominid and human evolution. In humans, the foot axis is on the second metatarsal bone. Research on plantar pressure distribution in bonobos and chimpanzees (Elftman \& Manter, 1935; Vereecke, D'Août, De Clercq, Van Elsacker, \& Aerts, 2003; Wunderlich \& Ischinger, 2017) has revealed that the functional foot axis of these two ape species is found on the second metatarsal bone, as is the case in humans. In contrast, macaque monkeys seem to have their functional axis on the third metatarsal and the center of pressure travels toward the third digit (Hirasaki, Higurashi, \& Kumakura, 2010).

This idea of a shift is supported by osteological studies. Given that plantar pressure data are limited, the functional foot axis is typically defined on the basis of the longest metatarsal, following the idea that the longest metatarsal bone functions as a lever during locomotion (Morton, 1922). Wunderlich (1999) reported that the second metatarsal is longer than the third metatarsal in hominoids. By contrast, the third metatarsal is the longest in most non-hominoid anthropoid species except for Ateles and Lagothrix, where the length of the second and third metatarsals is almost identical. Metatarsal robusticity (Marchi, 2005; Jashashvili, Dowdeswell, Lebrun, \& Carlson, 2015) and torsion (Drapeau \& Harmon, 2010; Pontzer et al., 2010) have also been used to define the functional axis of the foot and support the notion that there was a medial shift of the foot axis in hominoids.

Compared with osteological and foot pressure studies, myological evidence on this topic is relatively limited. We previously studied the plantar muscles of five primate species and found that the interosseous muscles seem to relate to the functional foot axis (Hirasaki \& Kumakura, 2010). In the foot, there are four dorsal (D1-D4) and three plantar (P1-P3) interosseous muscles. The dorsal interosseous muscles are bipennate, with each 
muscle arising mostly by two heads from the adjacent sides of the metatarsals. The plantar interossei are unipennate, originating mostly from the metatarsal of the toe into which the muscle is inserted. Both of the dorsal and plantar interossei are inserted mainly onto the bases of the proximal phalanges. One of the actions of the dorsal interossei is abduction of the digits at the metatarsophalangeal (MP) joints, whereas the plantar interossei adduct the digits. Thus, the digit that has insertions of the two dorsal interossei and no insertions of the plantar interossei is considered to be the foot axis. It is well known that the dorsal interossei of the human foot are arranged so that they abduct the digits around the second digit; the second digit has insertions of the first and second dorsal interossei (D1, D2) and no insertion of the plantar interosseous, suggesting that the functional foot axis is on the second digit (Fig. 1a). We refer to this as the "human condition" in this study. In contrast, the muscles of non-hominoid anthropoid primates are mostly arranged around the third digit (Howell \& Straus, 1933; Inokuchi, 1967), as is the case in the human hand: the third digit has insertions of D2 and D3 and no insertion of the plantar interosseous (Fig. 1b). We refer to this as the "monkey condition." This difference in the arrangement of the interosseous muscles is consistent with the results of osteological and plantar pressure studies and is thought to relate to the medial shift of the functional axis of the human foot, making the interossei "the most interesting muscles of the foot" (Manter, 1945).

In a previous study, we proposed a hypothesis concerning the transition from the monkey condition to the human condition (Hirasaki \& Kumakura, 2010). This transition requires that $\mathrm{D} 2$ changed its insertion from the third digit to the second digit and that the first plantar interosseous (P1) changed its insertion from the second digit to the third digit. Our hypothesis on how such an acrobatic jump in insertion actually occurred is based on detailed observations of the interosseous muscles of five primate species, which revealed that the dorsal interossei are composite muscles consisting of two parts, namely, the deep short flexors $(D S F)$ and the intermetatarsal abductors $(I M)$ positioned dorsal to the DSF (Cunningham, 1882; McMurrich, 1927). We hypothesize that changes in the combination of these fusions might exchange the insertions between D2 and P1, resulting in changes of the muscle arrangements from the monkey condition to the human condition (Fig. 2; also see Hirasaki \& Kumakura (2010) for details). That is, the monkey-type D2 (D2 $\mathrm{M}$ ), which consists of the second intermetatarsal abductor (IM2) and the fifth deep short flexor (DSF5), has its insertions on the third digit because DSF5 sends fibers to the third digit. 
120 If $I M 2$ changes its partner from DSF5 to DSF4, which has its insertion on the second digit, 121 then the muscles form the human-type $\mathrm{D} 2(\mathrm{D} 2 \mathrm{H})$, and DSF5 becomes the human type P1 $122\left(\mathrm{P} 1_{\mathrm{H}}\right)$.

123 To test this hypothesis, data on apes are essential. However, such information is 124 limited, and the available data are not necessarily in accord. For example, Lewis (1989), 125 Sokoloff (1972), and Swindler \& Wood (1973) reported that the interossei of chimpanzees are arranged around the third digit. By contrast, Hepburn (1892), Humphrey (1867), and Michaelis (1903) claimed that the second digit has insertions of the two dorsal interossei in chimpanzees. A similar discrepancy was found for gorillas (McMurrich, 1927).

The insertions of a muscle are relatively simple to determine. Thus, it is unlikely that these established researchers failed to correctly identify the insertions of the interossei. One possible reason for this discrepancy is intraspecific variation. However, as most previous reports were based on a single specimen, there is insufficient information to decide whether the discrepancy is due to intraspecific variation or other factors. If the great apes demonstrate both the human and monkey conditions, depending on individual subjects, we could infer that the chimpanzee arrangement of interosseous muscles is in a transitional stage from the monkey condition to the human one. In addition, if the great apes are in a transitional stage in terms of interosseous arrangement, this would suggest that modifications in the muscular system lagged behind those in the motion and skeletal systems because the foot functional axes estimated from metatarsal length and plantar pressure are already on the second digit in the great apes.

To test this idea, we examined the arrangement of the interosseous muscles in 14 great ape specimens, including 10 chimpanzees, 1 bonobo, and 3 gorillas. We predicted that some of the great ape subjects would represent the human condition and others the

\section{MATERIALS AND METHODS}

As described in Table 1, we examined 10 chimpanzees (Pan troglodytes), 1 bonobo 
(Jenny) was also used in Hirasaki \& Kumakura (2010) and four (Kanako, Journey, Pon, and Satoshi) in Oishi et al. (2012). All apes were obtained from zoos in Japan or the Kumamoto Chimpanzee Sanctuary of Kyoto University. All the zoo/sanctuary enclosures have a grass ground and artificial 3D structures on which animals can use a locomotor repertoire representative of their natural life, including knuckle walking, arm swinging, and climbing. No wild apes were included in this study. The apes were fully mature at the time of death and cadavers were preserved by freezing or $10 \%$ formalin solution. None of the apes showed any deformity or disorder related to locomotion.

Observations were made under a magnifying lens when necessary and photographed using a digital microscope. We concentrated on identifying insertions and the global form of the muscles.

\section{RESULTS}

In two of the 10 chimpanzees, the interosseous muscles were arranged around the second digit (Table 1). The second dorsal interosseous (D2) arose from the proximal half of the metatarsals II (fibular side) and III (tibial side), the medial cuneiform, and the sheath of the peroneus longus tendon and reached to the fibular side of the joint capsule of the MP joint II and the fibular side of the proximal phalanx II as a part of the dorsal aponeurosis. The first plantar interosseous (P1) arose with the second dorsal interosseous and reached to the tibial side of the proximal phalanx III as a part of the dorsal aponeurosis (Fig. 3a). The origins and insertions of the other interossei (the first, third, and fourth dorsals and the second and third plantar interossei) were the same as described in our previous study (Hirasaki \& Kumakura, 2010); that is, in these two specimens, the second digits had two insertions of the dorsal interossei and no insertions of the plantar interosseous, representing the human condition (the foot functional axis was on the second digit). In the other chimpanzee specimens, D2 reached to the tibial side of the MP joint III and the proximal phalanx III, and P1 was inserted on the fibular side of the MP joint II and the proximal phalanx II (Fig. 3b). The third digit had two insertions of the dorsal interossei, representing the monkey condition. Taken together, these findings 
demonstrate that variation exists in chimpanzees (Table 1 and Fig. 3). There was no clear relation between subspecies and interosseous arrangement.

Of the three gorilla specimens, which were all G. g. gorilla, one (Sakura) showed the human condition. Thus, intraspecific variation was also present in gorillas. The single bonobo specimen had its foot axis on the second digit. Interestingly, both the first plantar interosseous and the second dorsal interosseous could be observed in the dorsal view (Fig. 3c). Typically, only dorsal interossei are visible in the dorsal view.

$$
* * * * * * * * \text { Figure 3, around here } * * * * * * * *
$$

\section{DISCUSSION}

Our study revealed variation in the arrangement of interosseous muscles in great apes. Two of 10 (20\%) chimpanzees represented the human condition, in which the second digit has insertions of two dorsal interossei and no insertions of the plantar interosseous. These results are consistent with those of Hepburn (1892), Humphrey (1867), and Michaelis (1903). The other eight chimpanzee specimens represented the monkey condition, where the interosseous muscles are arranged around the third digit, which has two insertions of the dorsal interossei. These results are consistent with reports by Lewis (1989), Sokoloff (1972), and Swindler \& Wood (1973). In our gorilla specimens, one of three (33\%) showed the human condition, as previously reported by Lessertisseur \& Jouffroy (1973). We studied only one bonobo which had its foot axis on the second digit, unlike the findings by Miller (1952) and Vereecke et al. (2005). These results clearly demonstrate intraspecific variation in African great apes and support the hypothesis that their interosseous muscle arrangement is in a transitional stage from the monkey condition to the human one.

An interesting finding in this study was that our bonobo specimen showed a muscle arrangement in which both the second dorsal and first plantar interossei could be observed in a dorsal view (Fig. 3c). This was in accordance with the transitional condition shown in Figure 2b (Hirasaki \& Kumakura, 2010). In this condition, D2 was no longer bipennate and lost the origin on the second metatarsal. Instead, P1 expanded its attachment dorsally to the dorso-lateral aspect of the second metatarsal. This is similar to a frequently 
observed anomaly in human interosseous muscles reported by Manter (1945) where P1 increases in size such that it can be seen dorsally. Anomalies sometimes represent primitive conditions. We infer that this enlargement of P1 in the monkey condition may have been induced by an increase in force applied to the second MP joint during locomotion.

The arrangement of the interosseous muscles is thought to relate to the functional axis of the foot (Hirasaki \& Kumakura, 2010). Thus, the transitional stage of the interosseous muscle arrangement in African great apes may suggest that the functional foot axis is also in a transitional stage on the way to the medial shift, which is one of the most important factors in human foot evolution. As noted by Wunderlich (1999), however, the axis of the foot estimated from the metatarsal length is already on the second digit in apes. Studies based on robusticity (Marchi, 2005; Jashashvili et al., 2015) and torsion (Drapeau \& Harmon, 2010; Pontzer et al., 2010) of the metatarsal also suggest that the functional foot axis is on the second digit in the hominoids. Elftman \& Manter $(1934,1935)$, Vereecke et al. (2003), and Wunderlich \& Ischinger (2017) reported that the functional axis of the foot, as determined from foot pressure distributions, is on the second digit in chimpanzees and bonobos. Given these facts, we postulate that modification in the interosseous muscle arrangement phylogenetically lagged behind modification in metatarsal morphology and foot motion during locomotion. Modifications in foot motion during locomotion changed dynamic requirements to the musculoskeletal system, which may have induced modifications in morphology of the metatarsals and thus the arrangements of the interosseous muscles.

What induced the above-described modifications in foot motion? We infer that it was climbing behavior in hominoids. Wunderlich \& Ischinger (2017), who investigated plantar pressure distribution across the forefoot of chimpanzees during various locomotor repertoires, concluded that "the long, robust and inverted medial metatarsals in great apes are associated with greater plantar pressure medially than laterally during vertical climbing," based on experimental results indicating that peak pressure on the medial metatarsals and the first toe occurred at the end of stance phase during climbing and was higher than on any other element of the foot. In addition, toe pressure was considerably higher during vertical climbing than terrestrial knuckle walking or quadrupedal walking on horizontal poles. The great pressure applied on the medial part of the forefoot, 
particularly the second MP joint during vertical climbing, suggests that muscles around this joint generate a large plantar-flexion moment. The larger requirement at the second MP joint for plantar flexion may induce enlargement of $\mathrm{P} 1$ in the monkey condition $\left(\mathrm{P} 1_{\mathrm{M}}\right.$ or DSF4 in Fig. 2a, b), which serves to plantar flex the MP joint and abduct the digits. If this muscle develops well and merges with the dorsally located intermetatarsal abductor (IM2 in Fig. 2b), it may form a human-like D2 (D2 ${ }_{\mathrm{H}}$ in Fig. 2c) and the fifth deep short flexor (DSF5), which is part of D2 in the monkey condition, would be isolated as P1 in the human condition $\left(\mathrm{P}_{\mathrm{H}}\right.$ in Fig. 2c). Thus, the increased requirement for plantar flexion at the second MP joint could change the combination of fusions of the DSF and the IM. Given that DSF4 has its insertion on the second digit and DSF5 is on the third digit, a change in the combination could result in a change in the insertion of D2. As climbing is an important form of locomotion shared by non-human hominoids, it is plausible to attribute the medial shift of the functional foot axis in non-human hominoids to the biomechanical requirements of climbing behavior.

However, as climbing is no longer a part of the locomotor repertoire of humans, the question remains why humans retain the functional foot axis on the first or second metatarsal. We infer that this is linked to frequent bipedal walking. In our previous experimental study using macaque monkeys, the center of plantar pressure medially shifted during bipedal locomotion compared with quadrupedal locomotion (Hirasaki et al., 2010). At the late stages of the stance phase, the foot pressure center was somewhere between the second and third digits at the level of the metatarsal head in macaque monkeys (although the third digit is the last to take off from the ground). When pushing off the ground, dorsiflexion moment is applied on the second MP joint and the muscles resist by generating a plantar-flexion moment to stabilize the joint. Thus, the medial shift of the foot pressure center during bipedal walking requires increased activity of the plantar-flexion muscles at the second MP joint. Recently, Holowka, Hatala, Demes, Thompson, \& Wunderlich (2018) reported that their chimpanzee subjects exhibited lateral-to-medial roll-off patterns across the metatarsal heads during push-off of bipedal walking. Taken together, these experimental results for chimpanzees and macaque monkeys suggest that bipedal walking involves increased pressure at the medial forefoot. Considering that the myological axis of the foot on the second toe is consistently observed only in humans, the biomechanical requirement of obligate bipedal walking might be an 
important factor that changed the arrangement of the interossei from the monkey to human conditions. Conversely, intraspecific variation in the great apes might be associated with locomotor repertoires that exclude obligate bipedal walking. Our hypothesis concerning medial shift of the functional foot axis supports the biomechanical link between climbing and bipedalism (e.g., Prost, 1980; Fleagle et al., 1981; Yamazaki \& Ishida, 1984); however, at this stage, this is highly speculative and needs to be verified by additional mechanical data., but is highly speculative at this stage, and needs to be verified by additional mechanical data. Given the challenges of obtaining supporting experimental data, simulation studies using a musculoskeletal model may be able to clarify this assertion in the future.

\section{ACKNOWLEDGEMENTS}

We thank the following facilities for providing samples: Chausuyama Zoo, Himeji Central Park, Japan Monkey Center, Kamine Zoo, Kobe Oji Zoo, Tama Zoological Park, Ueno Zoological Gardens, and Yamajigoku. The samples were provided through the Great Ape Information Network (GAIN) and The Material Committee of Kyoto University Primate Research Institute. Dr. Daisuke Shimizu (Chubu Gakuin University) provided us with an opportunity to examine the bonobo specimen. We would like to express our gratitude to late Prof. Hiroo Kumakura (Osaka University) for his invaluable comments on the early stage of this study. This work was partly supported by The Japan Society for the Promotion of Science (Grants-in-Aid for Scientific Research, 15H04428 for EH), and the Cooperative Research Program of Primate Research Institute, Kyoto University.

\section{Authors' contributions:}

E. H. and M.O. conceived the study, designed the study, carried out the dissection work and wrote the manuscript. All authors gave final approval for publication.

\section{Conflict of interest statement:}

We declare we have no competing interests. 


\section{REFFERENCES}

Cunningham, D. J. (1882). Report on some points in the anatomy of the thylacine (Thylacinus cynocephalus), cuscus (Phalangista maculata) and phascogale (Phascogale calura) collected during the voyage of H. M. S. Challenger in the years 1873-1876: with an account of the comparative anatomy of the intrinsic muscles and nerves of the mammalian pes. Report on the scientific results of the voyage of $H . M$. S. Challenger during the years 1873-76, Zoology 5, Edinburgh: Neil and Co. for Her Majesty's Stationary Office.

Drapeau, M. S. M., Harmon, E.H., (2013). Metatarsal torsion in monkeys, apes, humans and australopiths. Journal of Human Evolution, 64, 93-108. DOI: 10.1016/ j.jhevol.2012.10.008.

Elftman, H., \& Manter, J. T. (1934). The axis of the human foot. Science 80 (2082), 484. DOI: $10.1126 /$ science.80.2082.484

Elftman, H., \& Manter, J. T. (1935). Chimpanzee and human feet in bipedal walking. American Journal of Physical Anthropology, 20, 69-79. DOI: 10.1002/ajpa.1330200109

Fleagle, J.G., Stern, J. T. Jr., Jungers, W. L., Susman, R. L., Vangor, A. K., \& Wells, J. P. 1981. Climbing: a biomechanical link with brachiation and with bipedalism. Symposia of the Zoological Society of London, 48, 359-375.

Hepburn, D. (1892). The comparative anatomy of the muscles and nerves of the superior and inferior extremities of the anthropoid apes. Part I. Journal of Anatomy and Physiology, 26, 149-186.

Hirasaki, E., \& Kumakura, H. (2010). Estimating the functional axis of the primate foot using the distribution of plantar muscles. International Journal of Primatology, 31, 239-261. Doi:10.1007/s10764-010-9395-5.

Hirasaki, E., Higurashi, Y., \& Kumakura, H. (2010). Dynamic Plantar Pressure Distribution during Locomotion in Japanese Macaques (Macaca fuscata). American Journal of Physical Anthropology, 142, 149-156. DOI 10.1002/ajpa.21240.

Holowka, N. B., Hatala, K. G., Demes, B., Thompson N. E., \& Wunderlich, R. E. (2018). Chimpanzee plantar pressure distributions and the evolution of bipedal plantigrady. American Journal of Physical Anthropology, 162 (S64), 124. 
Howell, A. B., \& Straus, W. L. Jr. (1933). The muscular system. In C. G. Hartman, \& W. L. Jr. Straus (Eds.), The Anatomy of the Rhesus Monkey (pp. 89-175). New York, NY: Hafner Publishing Co.

Humphrey, G. M. (1867). On some points in the anatomy of the chimpanzee. Journal of Anatomy and Physiology, 1, 254-268.

Inokuchi, S. (1967). On the muscles of the foot in Formosan monkey and crab eating monkey. Acta medica Nagasakiensia 11: 164-205.

Jashashvili, T., Dowdeswell, M. R., Lebrun, R., \& Carlson K. J. (2015). Cortical structure of hallucal metatarsals and locomotor adaptations in hominoids. PLOS ONE, 10.eos One, e0117905. DOI : 10.1371/journal.pone.0117905.

Lessertisseur, J., \& Jouffroy, F. K. (1973). Tendances locomotrices des primates traduites par les proportions du pied. Folia Primatologica, 20, 125-160. DOI: 10.1159/ 000155573

Lewis, O. J. (1989). Functional Morphology of the Evolving Hand and Foot. Oxford: Clarendon Press.

Manter, J. T. (1945). Variations of the interosseous muscles of the human foot. The Anatomical Record, 93, 117-124. DOI: 10.1002/ar.1090930203.

Marchi, D. (2005). The cross-sectional geometry of the hand and foot bones of the hominoidea and its relationship to locomotor behavior. Journal of Human Evolution, 49, 743-761. DOI: 10.1016/j.jhevol.2005.08.002.

McMurrich, J. P. (1927). The evolution of the human foot. American Journal of Physical Anthropology, 10, 165-171. DOI: 10.1002/ajpa.1330100202.

Michaelis, P. (1903). Beiträge zur vergleichenden Myologie des Cynocephalus babuin, Simia satyrus, Troglodytes niger. Archiv für Anatomie und Physiologie. Anatomische Abtheilung 1903: 205-256.

Miller, R. A. (1952). The musculature of pan paniscus. American Journal of Physical Anthropology, 91, 183-232. DOI: 10.1002/aja.1000910202

Morton, D. J. (1922). Evolution of the human foot. I. American Journal of Physical Anthropology, 5, 305-336. DOI: 10.1002/ajpa.1330050409.

Oishi, M., Ogihara, N., Endo, H., Une, Y., Ichihara, N., Asari, M., \& Amasaki, H. (2012). Muscle dimensions of the foot in the orangutan and the chimpanzee. Journal of Anatomy, 221, 311-317. DOI: 10.1111/j.1469-7580.2012.01545.x. 
377

378

379

380

381

382

383

384

385

386

387

388

389

390

391

392

393

394

395

396

397

398

399

400

401

402

403

Pontzer, H., Rolian, C., Rightmire, G.P., Jashashvili, T., Ponce de León, M.S., Lordkipanidze, D., \& Zollikofer, C.P. (2010). Locomotor anatomy and biomechanics of the Dmanisi hominins. Journal of Human Evolution, 58, 492-504. DOI: 10.1016/j.jhevol.2010.03.006.

Prost, J. H. (1980). Origin of bipedalism. American Journal of Physical Anthropology, 52, 175-189. DOI: 10.1002/ajpa.1330520204.

Sokoloff, S. (1972). The muscular anatomy of the chimpanzee foot. Gegenbaurs Morphologischen Jahrbuch, 119, 86-125.

Swindler, D. R., \& Wood, C. D. (1973). An Atlas of Primate Gross Anatomy: Baboon, Chimpanzee and Man. Seattle, WA: University of Washington Press.

Vereecke, E., D’Août, K., De Clercq, D., Van Elsacker, L., \& Aerts, P. (2003). Dynamic plantar pressure distribution during terrestrial walking of bonobos (Pan paniscus). American Journal of Physical Anthropology, 120, 373-383. DOI: 10.1002/ajpa.10163.

Vereecke, E. E., D’Août, K., Payne, R., \& Aerts, P. (2005). Functional analysis of the foot and ankle myology of gibbons and bonobos. Journal of Anatomy, 206, 453-476. DOI: 10.1111/j.1469-7580.2005.00412.x

Wunderlich, R. (1999). Pedal form and plantar pressure distribution in anthropoid primates. Ph.D. Thesis, State University of New York at Stony Brook, Stony Brook, NY.

Wunderlich, R. E., \& Ischinger, S. B. (2017). Foot use during vertical climbing in chimpanzees (Pan troglodytes). Journal of Human Evolution, 109, 1-10. DOI: 10.1016/j.jhevol.2017.04.006.

Yamazaki, N., \& Ishida, H. (1984). A biomechanical study of vertical climbing and bipedal walking in gibbons. Journal of Human Evolution, 13, 563-571. DOI: 10.1016/S0047-2484(84)80028-7. 
Figure 1.

407 Schematic of the arrangement of the foot interosseous muscles. a: "the human condition";

408 b: "the monkey condition"; I-V: the proximal phalanges I-V and the metatarsals I-V, respectively; solid lines: the dorsal interossei; dotted lines: the plantar interossei.

Figure 2.

412 Cross-sectional view of the metatarsal part of the foot, illustrating the hypothesis how the 413 arrangement of the interosseous muscles could change from "(a) the monkey condition" 414 to "(c) the human condition" via "(b) the transitional condition." II and III: cross-sections 415 of the second and third metatarsals, respectively; IM2: the second intermetatarsal 416 abductor in the primitive mammalian condition (Cunningham, 1882); DSF4 and 5: the 417 fourth and fifth deep short flexors in the primitive mammalian condition, which have their 418 insertions on the second and third digits, respectively; D2 $\mathrm{M}$ : the second dorsal 419 interosseous in the monkey condition, which is a composite muscle consisting of IM2 and 420 DSF5; $\mathrm{P} 1_{\mathrm{M}}$ : the first plantar interosseous in the monkey condition, which was DSF4 in 421 the primitive mammalian condition; $\mathrm{D} 2 \mathrm{H}$ : the second dorsal interosseous in the human 422 condition, which consists of IM2 and DSF4; $\mathrm{P}_{\mathrm{H}}$ : the first plantar interosseous in the 423 human condition, which was part of $\mathrm{D} 2 \mathrm{M}$ in the monkey condition.

Figure 3.

426 Examples of the results. a: dorsal view of the right foot of a chimpanzee specimen, 427 KUPRI\#7808, in which the second dorsal interosseous (D2) has its insertions on the 428 second digit; $\mathbf{b}$ : dorsal view of the right foot of a chimpanzee specimen, Yoshio, in which 429 D2 has its insertions on the third digit; c: the left foot of the bonobo specimen, Piisuke, 430 in which both the D2 and the first plantar interosseous (P1) are visible in the dorsal view; 431 II-V: the metatarsals II-V, respectively. 

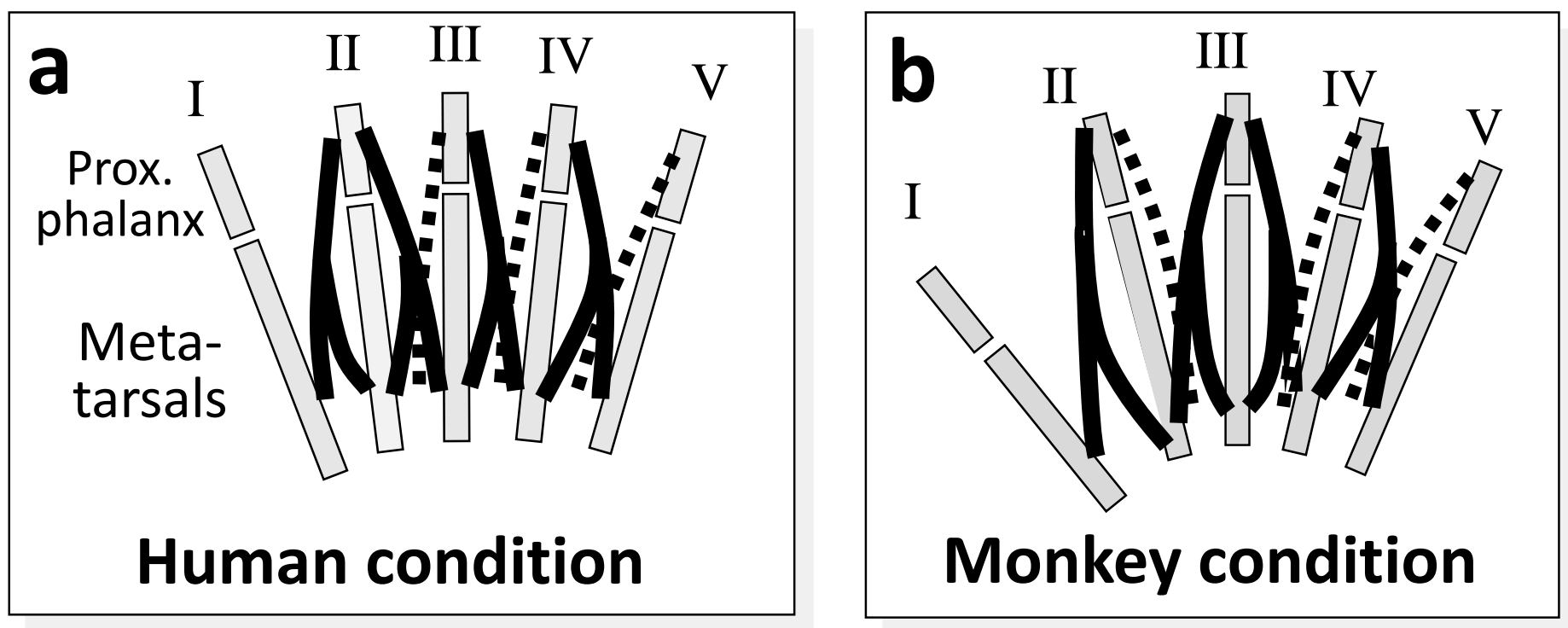

Figure 1 


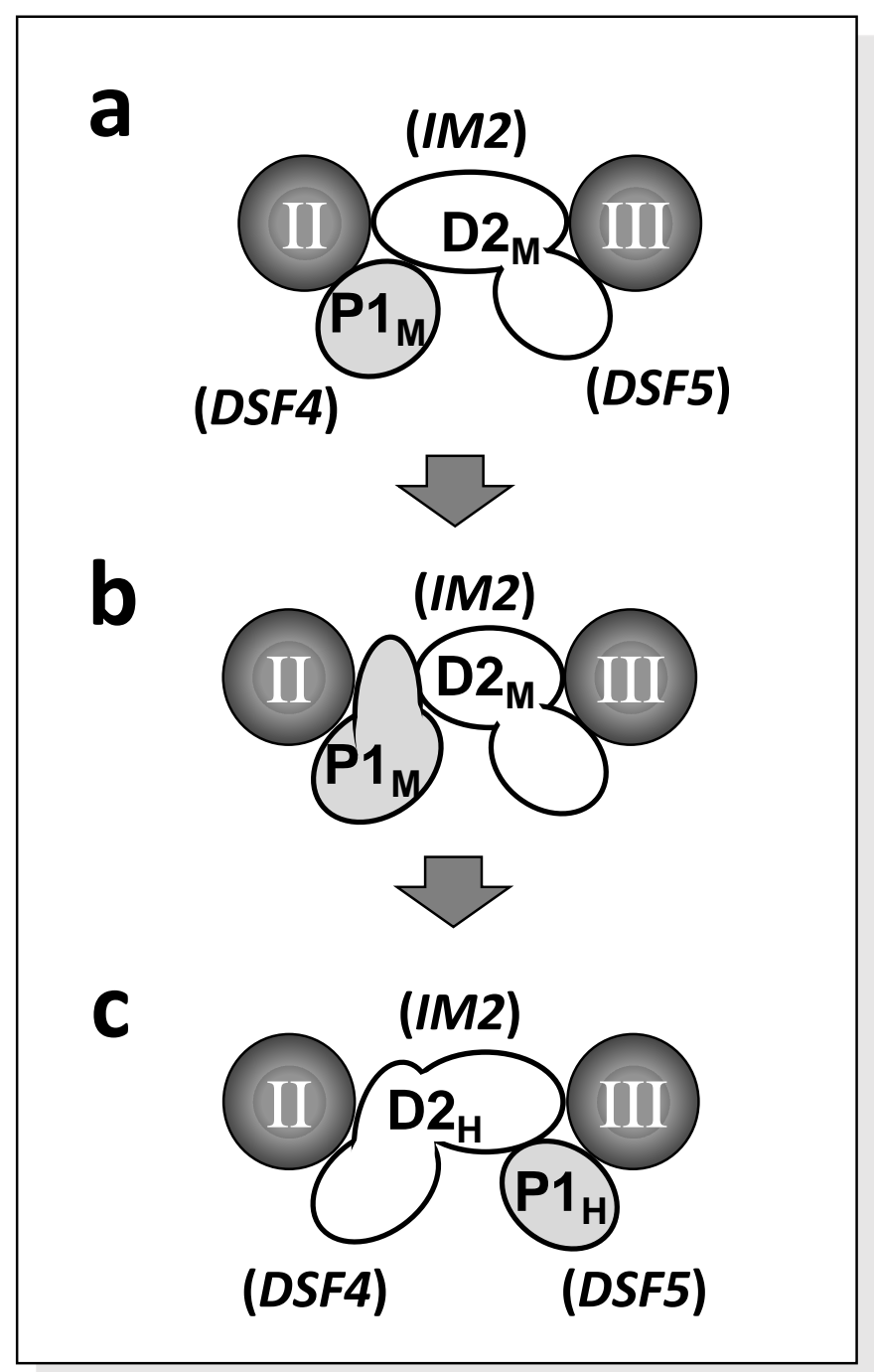

Figure 2 

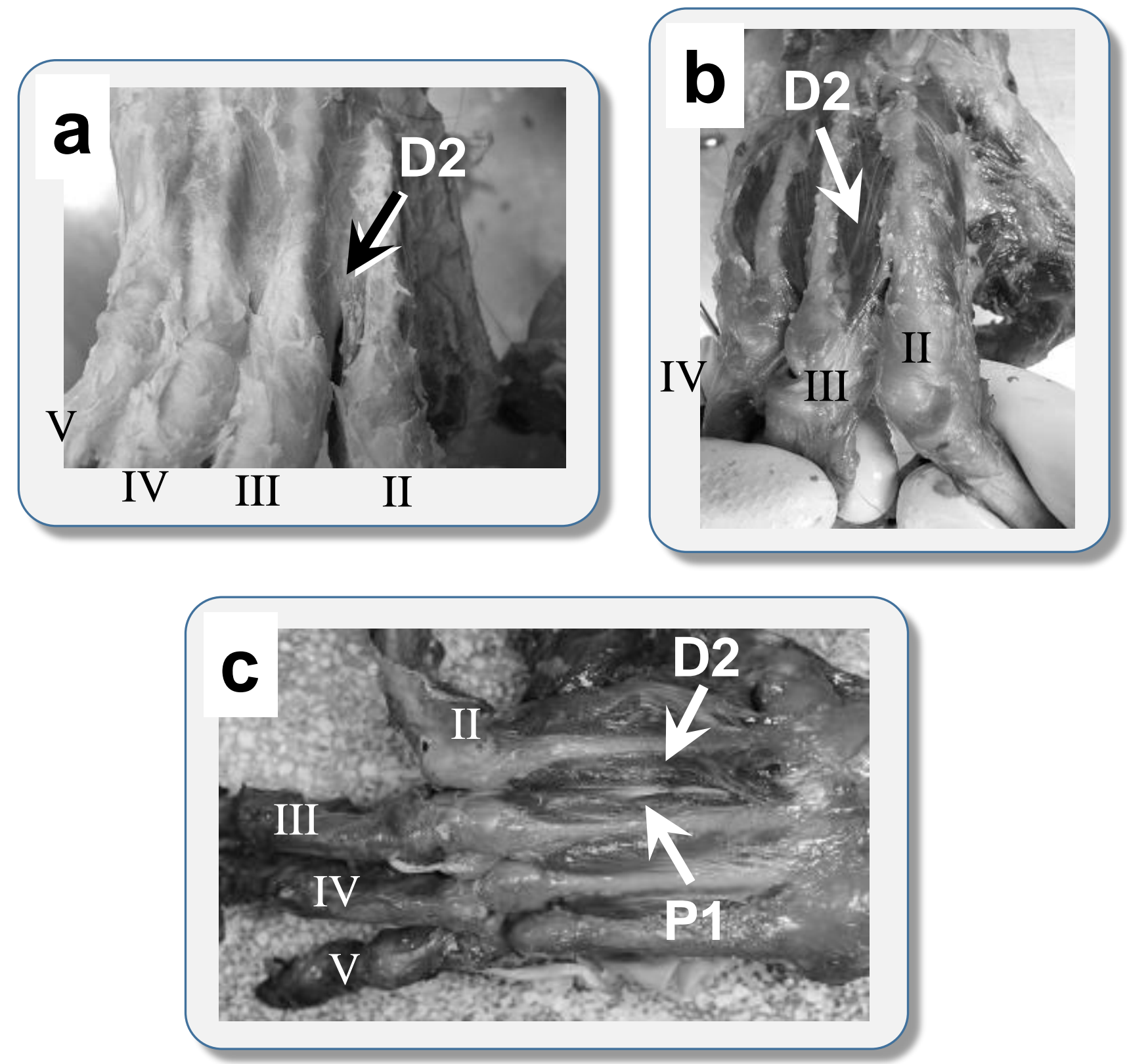

Figure 3 
Table 1. Details of the specimens examined

\begin{tabular}{|c|c|c|c|c|c|c|c|c|c|}
\hline Species & Subspecies & Name & Age & Sex & $\begin{array}{c}\text { Body mass at } \\
\text { death }\end{array}$ & Preservation & Side & $\begin{array}{l}\text { Zoo / } \\
\text { Institute }\end{array}$ & $\begin{array}{l}\text { Axis } \\
\text { digit* }\end{array}$ \\
\hline \multirow[t]{9}{*}{ Pan troglodytes } & verus & Kanako $^{1)}$ & 11 & $\mathrm{~F}$ & 30.2 & frozen & $\mathrm{L} / \mathrm{R}$ & Tama Zoological Park, Japan & III \\
\hline & verus & Journey $^{1)}$ & ca. 45 & $\mathrm{~F}$ & 44.0 & frozen & $\mathrm{L} / \mathrm{R}$ & Tama Zoological Park, Japan & III \\
\hline & verus & Reiko & ca. 47 & $\mathrm{~F}$ & 54.6 & frozen & $\mathrm{L}$ & Kyoto University, Japan & III \\
\hline & verus & Jenny ${ }^{2)}$ & (full adult) & $\mathrm{F}$ & $?$ & $10 \%$ formalin & $\mathrm{L} / \mathrm{R}$ & Kyoto University, Japan & III \\
\hline & verus & Macky & 38 & $\mathrm{~F}$ & $?$ & frozen & $\mathrm{R}$ & Tama Zoological Park, Japan & II \\
\hline & verus & Yoshio & 29 & M & 37.2 & frozen & $\mathrm{R}$ & Kyoto University, Japan & III \\
\hline & verus & Yuta & 24 & M & $?$ & frozen & $\mathrm{R}$ & Himeji Central Park, Japan & III \\
\hline & $\begin{array}{l}\text { schwein- } \\
\text { furthii }\end{array}$ & Pon $^{1)}$ & ca. 27 & M & 46.5 & frozen & $\mathrm{L}$ & Yamajigoku, Japan & III \\
\hline & hypbrid & Satoshi ${ }^{1)}$ & 27 & M & $?$ & frozen & $\mathrm{L} / \mathrm{R}$ & Chausuyama Zoo, Japan & III \\
\hline Pan paniscus & & Piisuke & ca. 29 & M & $?$ & frozen & $\mathrm{L}$ & Japan Monkey Centre & II \\
\hline \multirow[t]{3}{*}{ Gorilla gorilla } & gorilla & Reiko & 40 & $\mathrm{~F}$ & 69 & frozen & $\mathrm{L}$ & Ueno Zoological Gardens, Japan & III \\
\hline & gorilla & Daisuke & ca. 34 & M & 118.5 & frozen & $\mathrm{R}$ & Kamine Zoo, Japan & III \\
\hline & gorilla & Sakura & ca. 37 & $\mathrm{~F}$ & $?$ & frozen & $\mathrm{R}$ & Kobe Oji Zoo, Japan & II \\
\hline
\end{tabular}

* : The axis digit was defined as a digit which has two insertions of the dorsal interossei $\left(2^{\text {nd }}\right.$ and $\left.3^{\text {rd }}\right)$ and has no insertion of the plantar interosseous muscle.

1) Oishi et al. (2012);

2) Hirasaki and Kumakura (2010) 